\title{
Universidades internacionalizadas ou Universidade de Classe Mundial? Problematizações e tendências a partir do contexto latino-americano
} Internationalized universities or World Class University? Problematization and trends from the Latin American context

\author{
¿Universidades internacionalizadas o Universidades \\ de Rango Mundial? Problematización y tendencias \\ del contexto latinoamericano
}

Lara Carlette Thiengo ${ }^{1}$

Lucídio Bianchetti

DOI: http://dx.doi.org/10.20435/serie-estudos.v0i0.1390

\begin{abstract}
Resumo: Neste artigo, tem-se como objetivo analisar o lugar da internacionalização para edificação de Universidades de Classe Mundial (UCMs) e, de forma mais específica, como a internacionalização vem assumindo a "dianteira" na corrida pela excelência acadêmica/ou um perfil determinado de UCM nos países latino-americanos. Para isso, em termos metodológicos, utiliza-se a análise de documentos de Organismos Internacionais, de Planos de Desenvolvimento Institucionais de universidades latino-americanas com melhores posições nos rankings internacionais e de dados de questionários respondidos por pesquisadores do tema Educação Superior/Políticas de Educação Superior de Países da América Latina e do Caribe, a partir de uma plataforma on-line. Em linhas gerais, constata-se que há uma espécie de UCM de segundo tipo sendo forjada para os países que não compõem o eixo dinâmico do capital, garantindo a difusão do modelo, ainda que com adaptações. Nesse sentido, a internacionalização aparece como o grande eixo promotor da excelência para os países da região.
\end{abstract}

Palavras-chave: internacionalização; Educação Superior latino-americana; Universidade de Classe Mundial.

Abstract: The aim of this paper is to analyze the place of internationalization for the construction of World Class Universities (WCUs), and, more specifically, how internationalization has been taking the lead in the race for academic excellence/or a determined profile of WCU in the Latin

\footnotetext{
${ }^{1}$ Universidade Federal dos Vales do Jequitinhonha e Mucuri, Diamantina, Minas Gerais, Brasil.

${ }^{2}$ Universidade Federal de Santa Catarina, Florianópolis, Santa Catarina, Brasil.
} 
American countries. For this, in methodological terms, it is used the analysis of documents from International Organizations, Institutional Development Plans of Latin American universities with the best positions in the international rankings and data from questionnaires answered by researchers of Higher Education/Higher Education Policies in Latin American and Caribbean countries from an online platform. In general, it can be seen that there is a kind of second type of WCU being forged for countries that do not make up the dynamic axis of capital, ensuring the diffusion of the model, even with adaptations. In this sense, internationalization appears as the great axis that promotes excellence for the countries of the region.

Keywords: internationalization; latin american Higher Education; World Class University.

Resumen: El objetivo de este trabajo es analizar el lugar de internacionalización para la construcción de Universidades de Rango Mundial (URMs) y, más específicamente, cómo la internacionalización ha estado tomando la delantera en la carrera por la excelencia académica/o un perfil determinado de URM en los países latinoamericanos. Para esto, en términos metodológicos, se utiliza el análisis de documentos de Organizaciones Internacionales, Planes de Desarrollo Institucional de universidades latinoamericanas con las mejores posiciones en los rankings internacionales y datos de cuestionarios respondidos por investigadores de Educación Superior/Políticas de Educación Superior de Países de la América Latina y el Caribe desde una plataforma en línea. En general, se puede ver que hay una especie de segundo tipo de URM que se está forjando para países que no conforman el eje dinámico del capital, asegurando la difusión del modelo, incluso con adaptaciones. En este sentido, la internacionalización aparece como el gran eje que promueve la excelencia para los países de la región.

Palabras clave: internacionalización; Educación Superior latinoamericana; Universidad de Rango Mundial.

\section{INTRODUÇÃO}

Não por acaso, de forma frequente, confunde-se a concepção de Universidade de Classe Mundial (UCM) ${ }^{3}$ com a concepção de internacionalização, ou seja, uma "Universidade internacionalizada", uma vez que esta representa a principal condição para constituir uma UCM.

\footnotetext{
${ }^{3} \mathrm{O}$ modelo refere-se à constituição de universidades ou grupo de universidades que tenham um propósito específico: o de representar globalmente o Ensino Superior nacional em sua capacidade de gerar desenvolvimento econômico e conhecimento na área científica, tecnológica e de inovação. Neste sentido, as UCMs, além de produzirem pesquisas, devem responsabilizar-se pela formação de cientistas e pesquisadores que, se espera, venham a ocupar postos fundamentais de trabalho na economia, gestão e nos processos de geração de conhecimento, em apoio aos sistemas nacionais de inovação. De acordo com os documentos dos Organismos Internacionais (Ols), especialmente o Banco Mundial (SALMI, 2009), considera-se que as características centrais para a constituição de uma UCM são: alto nível de internacionalização (para atração de talentos); investimento alto e diversificado; gestão flexível e transferência de tecnologia/interação com o setor produtivo (inovação), entre outras.
} 
Por esse motivo, neste artigo, temos como objetivo analisar o lugar da internacionalização para edificação de Universidades de Classe Mundial e, de forma mais específica, como a internacionalização vem assumindo a "dianteira" na corrida pela excelência acadêmica nos países latino-americanos.

Como viemos tratando em outras produções (THIENGO; ALMEIDA; BIANCHETTI, 2019a, 2019b), compreendemos, a partir da análise dos documentos dos Organismos Internacionais (Ols) e seus intelectuais, que vem sendo elaborado e difundido um consenso acerca da necessidade de cada país possuir uma UCM. Isto ocorre até mesmo com aqueles países que não têm condições de compor os primeiros lugares nos rankings, mas, a despeito disto, contam com Instituições de Ensino Superior (IESs) que se destacam em suas regiões, agrupamentos ou blocos, como ocorre em alguns países da América Latina e do Caribe (ALeC). Assim, como verificamos em Thiengo, Almeida e Bianchetti (2019a), para os países que não fazem parte do eixo dinâmico do capital, outro perfil de UCM vai sendo definido, sendo este essencialmente pautado na criação de centros/nichos de excelência e a criação de grupos e redes de pesquisa com ênfase internacional.

Para atender ao objetivo proposto, lançamos mão: a) da análise de documentos dos Ols; b) análise dos Planos de Desenvolvimento Institucional das instituições latino-americanas que se destacam nas classificações de três principais rankings acadêmicos internacionais ${ }^{4}$ e c) também de trabalharmos com uma parcela de dados coletados por um questionário endereçado a pesquisadores do tema Educação Superior/Políticas de Educação Superior de Países da América Latina e do Caribe.

Os questionários foram elaborados do sistema on-line encuesta fácil e enviado a 25 pesquisadores da referida sub-região. Do total enviado, tivemos 15 respondentes, sendo 12 deles de forma completa (até o final do formulário). De modo geral, tivemos questionários respondidos por pesquisadores do Brasil, México, Argentina, Colômbia e Chile. Para este artigo, selecionados o eixo de perguntas especificamente relacionado à internacionalização, bem como algumas perguntas sobre conhecimento do modelo de UCM. Em tempo, cabe ressaltar que o perfil dos entrevistados é formado, em maioria, por professores pesquisadores da Educação Superior, também vinculados a Programas de Pós-Graduação e com mais de 15 anos de experiência como acadêmicos.

\footnotetext{
${ }^{4}$ Times Higher Education, QS e Ranking Shangai.
} 


\section{INTERNACIONALIZAÇÃO E "ATRAÇÃO DE TALENTOS": PRESSUPOSTO BÁSICO DO MODELO DE UCM}

De saída, consideramos coerente apresentar, ainda que de modo sucinto - levando-se em conta os limites espaço-tempo deste artigo -, algumas considerações sobre o conceito de Internacionalização da Educação Superior.

De acordo com Morosini (2011), tal conceito é bastante complexo e possui uma diversidade de termos relacionados, apresentando diversas fases de desenvolvimento ${ }^{5}$. A referida autora levanta compreensões de alguns autores sobre a compreensão de internacionalização. A seguir, apresentamos algumas delas, considerando suas contribuições para o debate ora proposto.

Bartell (2003) conceitua a Internacionalização como trocas internacionais relacionadas à educação e a Globalização como uma avançada fase no processo que envolve a internacionalização. $O$ autor aponta diversas formas de realizar a internacionalização: presença de estrangeiros e estudantes-convênios num determinado campus; número e magnitude de concessões de pesquisa internacional; projetos de pesquisa internacionais cooperativados; associações internacionais envolvendo consultoria para universidades estrangeiras e outras instituições; setores de universidades privadas com metas internacionais; cooperação internacional e colaboração entre escolas, conselhos e faculdades na universidade; e o grau de imersão internacional no currículo, entre outros. Outras posições identificam a internacionalização como um processo na universidade como um todo. As estratégias para atingir este conceito abarcam cursos para executivos de negócios; aumento de contatos com estudantes internacionais e professores, exportação de MBA; estabelecimento, via Internet, de campi em outros países, ou oferecimento de contratos de capacitação para executivos de negócios ou oficiais do governo; atração de estudantes internacionais, formando colaborações de pesquisa, provendo cursos de treinamento em outros países ou, ainda, realizando marketing de educação à distância. (GREEN;

\footnotetext{
${ }^{5}$ Para Morosini (2011), são citadas: a) dimensão internacional - presente no século XX, que se caracteriza por ser uma fase incidental mais do que organizada; b) educação internacional - atividade organizada prevalente nos Estados Unidos, entre a Segunda Guerra Mundial e o término da Guerra Fria, preferentemente por razões políticas e de segurança nacional; e c) internacionalização da Educação Superior, posterior à Guerra Fria e com características de um processo estratégico ligado à globalização e à regionalização das sociedades e seu impacto na Educação Superior.
} 
BAER, 2001) Marginson e Rhoades (2002) conceituam Internacionalização como a globalização do ensino superior, o desenvolvimento do aumento de sistemas educacionais integrados e as relações universitárias além da nação. Estes autores conceituam também Capitalismo acadêmico, que identifica uma tendência global de privatização na educação superior, com todas as características inerentes, inclusive com destaque ao lucro. (MOROSINI, 2011, p. 117).

Neste sentido e a partir das pesquisas que viemos desenvolvendo nos últimos anos, podemos afirmar que a internacionalização é apresentada pelos Ols e seus intelectuais como um dos principais fatores na "busca pela excelência"/ pelo modelo de UCM, uma vez que é importante na concentração de talentos, ou seja, "a grande afluência de estudantes estrangeiros pode ser fundamental para melhorar o nível acadêmico da população estudantil" (SALMI, 2009, p. 46). $\mathrm{O}$ autor destaca a habilidade e a capacidade que essas universidades têm de apresentar altos índices de internacionalização, considerando a mobilidade de alunos e professores que estabelecem intercâmbio e projetos de cooperação internacional. Por isso, programas assim ocupam lugar estratégico na gestão de recursos das universidades deste tipo.

De modo geral, em virtude da procura internacional e da política de recrutamento por melhores alunos, as UCMs contam com uma população numerosa de alunos estrangeiros. Além disso, essas universidades detêm uma proporção alta de acadêmicos de outros países em seus quadros de docência. Para reforçar esta ideia, em documento do BM, Salmi (2009) informa que, em Harvard, a proporção de professores estrangeiros no quadro de docência é próxima de um terço. Em Oxford e Cambridge, a taxa é de 36\% e 33\%, respectivamente.

A publicação da Unesco (SADLAK; CAI, 2009) utiliza-se de dados da OCDE para evidenciar que um grande número de países procura manter vantagem competitiva no mercado global implementando políticas e incentivos econômicos que facilitem a aquisição de tais "trabalhadores do conhecimento" mediante a oferta de bolsas de estudo, de bolsas e financiamentos para projetos, de subsídios e benefícios fiscais. Desse modo, "os países estão atraindo professores e pesquisadores de renome para produzir resultados de pesquisa de ponta em todos os campos acadêmicos e, consequentemente, estão criando departamentos universitários de classe mundial" (SADLAK; CAI, 2009, p. 15). 
No mesmo documento são apontados também os esforços realizados pelos países para proporcionar condições jurídicas e sociais mais atraentes para pesquisadores estrangeiros. Outra questão relevante apontada pelo referido documento em relação à concentração de talentos é o "efeito bola de neve", que pode gerar ainda outro efeito - o agrupamento (clustering). De acordo com os dados apresentados na publicação da Unesco, é comum que os melhores pesquisadores de várias áreas estejam agrupados em algumas universidades do mundo. Assim, "as universidades que têm um matemático ou um químico altamente citado são desproporcionalmente propensas a ter outros no mesmo campo, e isso não se dá apenas porque elas são universidades grandes ou famosas" (SADLAK; CAI, 2009, p. 147), o que pode ser compreendido como efeito bola de neve.

Segundo Robertson (2010), instituições competem tanto por corpo docente "de elite" quanto por estudantes, o que faz com que irrompa um "mercado de cérebros". Os fatores de atração combinam estruturas bem equipadas, condições de pesquisa e altos salários. De acordo com a Unesco (SADLAK; CAI, 2009), as universidades das pequenas nações lutam para atrair talentos acadêmicos (pesquisadores altamente citados), uma vez que estejam em desvantagem na utilização deste indicador nos rankings internacionais.

Segundo Altbach et al. (2012), na maioria dos países industrializados, as trajetórias individuais das carreiras docentes são refletidas em salários diferenciados, o que, na perspectiva dos autores, é fundamental para o desenvolvimento futuro de uma "cultura de excelência". Em alguns países da OCDE, por exemplo, a flexibilidade de financiamento propiciada pelas Research Excellence Initiatives (REIs) permite oferecer aos professores estrangeiros pacotes muito atraentes em termos de instalações de pesquisa, pessoal de suporte e salários ${ }^{6}$, assim como condições de trabalho mais razoáveis para professores destacados da própria instituição, como a diminuição do número de aulas, possibilitando maior dedicação à área da pesquisa.

O movimento em busca da atração de talentos, por outro lado, aprofunda o que os pesquisadores entendem como brain drain ou "fuga de cérebros". De

\footnotetext{
${ }^{6}$ Em alguns casos, como na Dinamarca, os salários dos investigadores não podem ser negociados livremente, e nenhum dos investigadores é dispensado de tarefas administrativas regulares ou de obrigações de ensino.
} 
acordo com Araújo e Ferreira (2013), a primeira expressão refere-se aos fluxos de força de trabalho altamente qualificada de países subdesenvolvidos para países mais desenvolvidos, enquanto a segunda expressão trata da saída de população qualificada de um país mais desenvolvido para outro localizado na mesma posição. Para os referidos autores, "[...] esta fronteira é notória [...] no seio dos discursos políticos, particularmente nos países desenvolvidos com mais dificuldades em aceder a posições centrais nos domínios da ciência, da tecnologia, da inovação e da competitividade" (ARAÚJO; FERREIRA, 2013, p. 80).

Neste sentido, não seria novidade afirmar que a atração de talentos é tratada nos documentos analisados como expressão da mobilidade internacional, sendo esta uma característica apresentada como positiva no bojo do processo de internacionalização da Educação Superior. Ainda que existam ressalvas quanto a alguns pontos, ${ }^{7}$ a mensagem que se emite pelos documentos, de modo geral, estabelece como critérios para tornar-se uma Universidade de Excelência: i) cultivar o seu próprio pessoal (identificar e reter os melhores pesquisadores em uma fase precoce), ii) atrair os melhores pesquisadores e iii) colaborar com os melhores.

Por tais motivos, todas as publicações utilizadas neste documento asseveram o imperativo da Língua Inglesa no processo de constituição das Universidades de Excelência, já que a principal característica desse modelo de universidade é a internacionalização.

Em consonância com o exposto, evidencia-se a necessidade de um "novo tipo de docente", que esteja inserido em uma "cultura da investigação" em que a "produtividade científica" deve ser alta (ALTBACH; SALMI, 2011).

Os professores também "devem ter consciência de sua essência internacional” (ALTBACH; SALMI, 2011, p. 20,), considerando colaborar com colegas que residem em países diferentes. No que se refere às jornadas de trabalho destes docentes, elas devem ser "modestas", para que a maior parte do tempo possa ser dedicada às atividades de investigação. A disponibilidade para mobilidade e a procura por melhores condições de trabalho e por carreiras mais promissoras também são colocadas como características deste perfil de profissional, avaliadas

\footnotetext{
${ }^{7}$ Por exemplo, os problemas relacionados à concentração de pesquisadores em alguns países ou instituições.
} 
de forma positiva. Sobre este aspecto, Silva Júnior (2015, p. 148), entende que se busca transformar o docente em um captador de recursos ou gestor de projetos, reconfigurando o próprio conceito de docência e pesquisa. O Estado, nesta perspectiva, pressupõe que o docente é potencialmente um empreendedor e, por isso, institui mecanismos de indução para que ele se adéque às atividades inerentes à profissão, de acordo com os resultados estabelecidos pelos interesses do mercado.

Entretanto é importante esclarecer que o processo de internacionalização universitária não se refere apenas à mobilidade de estudantes e pesquisadores, visto que também abarca uma variedade de elementos como currículo, ensino-aprendizagem, pesquisa, acordos institucionais e a cooperação internacional para "responder" às novas demandas da globalização, como se pode perceber no seguinte trecho do documento do BM:

[...] para facilitar a contribuição de estudiosos estrangeiros, um número de universidades que aspiram a ser de classe mundial formou parcerias de sucesso com as principais universidades dos países industrializados. Este foi o caso dos Institutos Indianos de Tecnologia nos primeiros anos de sua criação. (SALMI, 2009, p. 46).

Há ainda que se considerar o viés econômico da mobilidade internacional. De acordo com a Unesco (SADLAK; CAI, 2009, p. 50, tradução nossa), "os alunos procuram a melhor instituição possível, muitas vezes, independentemente das fronteiras nacionais". Desse modo, "a posição global ocupada por essas instituições está se tornando cada vez mais uma preocupação importante para as instituições ao redor do mundo".

Temos assim que a centralidade adquirida pela concentração de talentos para o modelo de UCM expressa pelo menos dois movimentos, que nos ajudam a compreender o papel desta concepção de universidade no sistema do capital.

O primeiro deles é o mercado criado no âmbito da mobilidade internacional de alunos e docentes, que, de acordo com Altbach et al. (2012), representa uma indústria de 45 bilhões de dólares, com capacidade para triplicar este valor até o ano de 2020. Outros dados que evidenciam esse cenário são os índices de mobilidade acadêmica do International Institute of Education (IIE), os mais altos das últimas séries históricas (SILVA JÚNIOR, 2015). Dessa forma, uma universidade que 
atraia muitos alunos estrangeiros em virtude de programas de internacionalização será capaz de auferir receitas adicionais.

Sobre esse processo, ao elaborar o estado da arte sobre os modelos de internacionalização, Morosini (2011) afirma que o Modelo de Cooperação Internacional Tradicional se caracteriza justamente pela captação de sujeitos e de consumidores entre as instituições. Diante do exposto, entendemos que este movimento expressa a forma como o modo de produção capitalista mercantiliza as relações - neste caso, a mobilidade de estudantes - e desenvolve contradições, ou seja, torna tal mobilidade envolvente e participativa em sua aparência.

Nesse contexto, é importante salientar também que o elemento cultural é parte constituinte das relações nas esferas econômica, política e social. Ratificamos com este exemplo que a hegemonia do sistema capitalista, para além das relações de produção, é concomitantemente elaborada no âmbito da produção do consenso, a partir da naturalização deste tipo de sociabilidade.

O segundo movimento está relacionado à formação para o trabalho complexo, que deve levar em consideração, durante a sua realização, as áreas estratégicas dos distintos países, em consonância com o processo de mundialização do capital. De acordo com Sguissardi (2014) e Silva Júnior (2015), este novo momento do capitalismo caracteriza-se pela descentralização de grandes empresas, cujas unidades multiplicam-se e espalham-se por diversas regiões e países em busca de menores custos e maiores vantagens quanto à força de trabalho (mais barata), matéria-prima e legislação trabalhista mais flexível, demandando, para tanto, universidades que pesquisem e formem força de trabalho especializada para empresas com subsídio estatal.

Por fim, corroborando com Maués (2015), entendemos que a educação e a produção do conhecimento se tornam alvos privilegiados da internacionalização, se a considerarmos como parte do processo de mundialização do capital. Assim, percebemos que, se a educação já vem de há muito sendo apontada como um dos principais fatores ligados ao desenvolvimento econômico, a concepção de UCM está direcionada de forma mais objetiva e direta para o seu incremento, ou seja, como mencionamos anteriormente, a partir do "mercado da mobilidade", da potencialização da força de trabalho em áreas temáticas e geograficamente estratégicas e da atração de cérebros para promoção da inovação. 


\section{PERSPECTIVA DE INTERNACIONALIZAÇÃO NOS PLANOS DE DESENVOLVIMENTOS INSTITUCIONAIS/ESTRATÉGICOS EM UNIVERSIDADES DA ALEC: INTERNACIONALIZAÇÃO COMO PROMOÇÃO DA EXCELÊNCIA}

Considerando os PDIs analisados, é possível perceber que as IESs brasileiras, em termos propositivos, apresentam-se mais organizadas e diretamente comprometidas a tornarem-se UCMs - o que também varia entre as universidades analisadas. Passando às universidades dos outros países da América Latina que vêm se destacando nos rankings internacionais, percebemos que, de modo geral, a aspiração para a excelência aparece de forma menos desenvolvida Isto é, apesar de os discursos que compõem os planos analisados estarem em consonância com as IESs brasileiras, especialmente no que se refere à internacionalização e à ampliação da pós-graduação, percebemos que nenhuma das IESs não brasileiras apresentou como objetivo tornar-se UCM ou estar classificada entre as melhores IESs do mundo nos rankings internacionais.

Todavia, de forma geral, um elemento comum, considerando sua presença e força (centralidade), é a internacionalização.

Os PDIs de todas as instituições brasileiras analisadas evidenciam que um dos principais valores da excelência das IESs é a internacionalização. A ideia central que embasa tais argumentos é a tendência global em relação ao Ensino Superior, tida como necessária para que as IESs brasileiras possam se adequar aos padrões internacionais da Educação Superior.

Tendo em vista o exposto, é notório que as IESs têm como objetivo fortalecer as suas relações internacionais, de forma a assegurar a sua transformação em UCM, a partir da consolidação e da cooperação bilateral e multilateral com instituições internacionais, com programas de mobilidade acadêmica docente, discente e de técnico-administrativos, assim como a atuação política e acadêmica juntamente de grupos universitários e em programas internacionais, com a inclusão de novas modalidades de cursos binacionais. De igual modo, planejam adequar ou reformular a infraestrutura de Relações Internacionais e investir na melhor divulgação das informações sobre a universidade considerando o cenário internacional.

Nessa perspectiva, outra questão abordada é a necessidade de cursos preparatórios de línguas para discentes e docentes, o que se dá mediante oferta de cursos em Inglês e Espanhol, de cursos em Português para estrangeiros e aumento 
do número de cursos/disciplinas em Inglês, sendo este último um ponto fulcral para a constituição de uma instituição internacional.

Nos PDIs, relata-se também a heterogeneidade dos processos de internacionalização dentro das universidades, que estão centrados em algumas áreas ou departamentos. Ademais, são mencionados problemas em relação ao excesso de burocracia dentro das universidades, pouca qualificação dos funcionários ligados ao processo de internacionalização, no que se refere ao domínio de outras línguas, e falta de informações sobre procedimentos de imigração e de condições ideais para acolhimento de estrangeiros.

Outra caraterística importante, que por vezes se confunde com a concepção de Classe Mundial, é a internacionalização, uma vez que esta representa a principal condição para constituir uma UCM.

De acordo com o PDI da USP (2011, p. 30):

[...] como Universidade de classe mundial, a USP busca maior inserção em instituições estrangeiras, promovendo viagens de professores, de estudantes (graduação e pós-graduação) e de funcionários. Receber estrangeiros, ampliar convênios, promover pesquisas conjuntas e planejar parcerias estratégicas significa fortalecer a posição da USP na comunidade internacional. O processo deve ser bidirecional, mas atualmente há nítido desequilíbrio, pois se observa maior fluxo da Universidade para o exterior. A Comissão Permanente de Avaliação e as comissões avaliadoras externas detectam deficiências sistemáticas na coleta de dados relativos à internacionalização. A análise dos números atuais, a tendência dessa inserção e a ausência de indicadores consistentes acusam a necessidade de ações específicas para que a USP possa atrair mais estrangeiros.

Passando às demais IESs analisadas (região latino-americana), a PUC do Chile, de acordo com seu Plan de Desarrollo (2015-2020), é uma instituição comprometida em consolidar a sua liderança no cenário regional e também internacional, que deve acontecer com a melhor gestão e expansão da internacionalização (especialmente nos Programas de Doutorado) a partir de boas práticas alcançadas através de uma estreita vinculação com universidades e centros de classe mundial.

É importante destacar, todavia, que esta universidade não se considera uma instituição de classe mundial, mas sim entende como fundamental a articulação com estas IESs como fonte de aquisição/aprendizagem do "como se faz". Neste mesmo sentido, outra linha de ação é "fortalecer la investigación de excelencia a 
través de facilitar la cooperación internacional, especialmente en aquellas áreas donde tenemos mayores fortalezas" (PUC CHILE, 2015, p. 43). A concentração de talentos, uma das principais características do modelo de UCM, é apresentada pela PUC CHILE sob a perspectiva da inclusão, reforçando o viés meritocrático.

No Plano de Desenvolvimento Institucional da Universidad Nacional Autónoma de México (UNAM), as questões da internacionalização e da inovação ganham certa expressividade, contudo não destoam de forma significativa em proporção e ênfase do documento, considerando o documento em sua completude. Verificamos que a internacionalização é apresentada como uma demanda dos novos tempos que não pode ser deixada de lado, principalmente em consequência da necessária cooperação entre os países, sobretudo da região.

Neste mesmo sentido, a preocupação com a Língua Inglesa também é premente no documento, indicando a necessidade de desenvolvimento de estratégias acadêmicas para fortalecer o ensino de Inglês e a necessidade de promoção da mobilidade acadêmica, construção de redes e ampliação do marketing internacional.

Entre as estratégias do Plano do ITMS, também percebemos ênfase na internacionalização de alunos e professores, bem como em "atrair alunos e professores estrangeiros" e fortalecer alianças nacionais e internacionais com "empresas, universidades, organizações da sociedade civil, fundos e outras instituições para realizar projetos e compartilhar recursos" (ITMS, 2015 p. 23). São comuns referências à atração de talentos e pessoas com alto potencial de liderança, o que vai ao encontro da perspectiva de UCM.

Por fim, no PDI da Universidad de los Andes (Colômbia), instituição que nos últimos anos vem ganhando posições nos rankings acadêmicos internacionais, percebemos que o objetivo de alinhamento aos estandartes internacionais permeia todo o plano - em relação ao corpo docente, qualidade dos cursos, internacionalização e outras -, apesar de não ocorrerem declarações sobre o objetivo de tornar-se uma UCM.

A internacionalização da IES ganha relevo no documento, visto que todo um eixo tem como objetivo traçar estratégias para ampliar sua visibilidade e o seu impacto. Não podemos deixar de destacar que, de modo geral, as IESs têm como objetivo fortalecer as suas relações internacionais, a partir da consolidação e da cooperação bilateral e multilateral com instituições internacionais, com programas de mobilidade acadêmica docente, discente e de técnico-administrativos, assim 
como a atuação política e acadêmica juntamente de grupos universitários e em programas internacionais, com a inclusão de novas modalidades de cursos binacionais.

Considerando o exposto, percebemos que, nos países latino-americanos, os quais ocupam lugar periférico na Divisão Internacional do Trabalho, as principais IESS orientam-se no sentido de internacionalizarem-se a partir de redes de pesquisas, mobilidade acadêmica e estudantil e em parceria com universidades consideradas de Classe Mundial, o que reforça sua posição de dependência em termos de produção científica e tecnológica, ao mesmo tempo em que garante o mercado da mobilidade internacional.

\section{INTERNACIONALIZAÇÃO NAS UNIVERSIDADES LATINO-AMERICANAS SOB O OLHAR DE PESQUISADORES DA ÁREA}

Para avançar nas discussões sobre o tema, como indicamos na introdução deste artigo, lançaremos mão de alguns dados do questionário "Universidade de Classe Mundial na América Latina" - especialmente sobre a internacionalização -, que foi enviado a pesquisadores da Educação Superior de diferentes países da sub-região em pauta e respondido por eles.

Apesar de os PDIs analisados, em sua maioria, não expressarem literalmente o objetivo de tornarem-se UCM (ainda que os valores do modelo já estejam implicados nos referidos documentos), todos os pesquisadores respondentes alegaram ter conhecimento sobre a concepção de UCM.

Considerando as respostas à pergunta "O que entende como uma Universidade de Classe Mundial? Acredita que este deve ser um objetivo a ser perseguido por todas as universidades e também por todos os países?", apenas um dos pesquisadores afirmou conhecer e estar de acordo com a perspectiva, diferenciando-se dos demais, que alegaram ter conhecimento sobre o modelo, mas apresentaram, em nível mais ou menos elaborado, críticas ao modelo. A seguir, destacamos algumas respostas:

[...] se corresponde con la tendencia mundial actual y dominante de los modelos emergentes de universidad que surgieron en estados unidos y que ahora han sido adoptados de forma generalizada en algunos países de Europa, pero sobre todo de China, Corea, Japón, Singapur, Tailandia y Malasia, todo ellos orientados, con sus diferencias de contexto, por el mercado. (PESQUISADOR 5). 
Este discurso se formula en el marco de la promulgación de los rankings internacionales y el estímulo de la competitividad entre instituciones de lo que ahora se denomina educación terciaria. Para agencias como el Banco Mundial, una universidad de clase mundial (UCM) es aquella que conjuga un alto nivel de recursos (provenientes de los sectores oficial y privado), un alto nivel de talento en sus profesores y estudiantes y un manejo de la gobernabilidad caracterizado por la flexibilidad, la innovación y la gestión eficiente. Este discurso tiene unos propósitos y un sentido particular en el marco del neoliberalismo contemporáneo que impulsa a las universidades a asumirse como empresas altamente productivas y competitivas, y que por tanto, se adscriben a las exigencias de contribuir al crecimiento económico y al desarrollo de las metas de la economía del conocimiento. Frente a la otra pregunta la reformularía, pues considero que este no deber ser el papel de ninguna universidad ni este es el proyecto pertinente para ningún país que asuma el carácter de la educación como bien público y como derecho de todos. (PESQUISADOR 3).

Para ser assertivo e diretamente ir além do fenômeno defino a World Class University como uma instituição prestadora de serviços em âmbito mundial. Seus serviços variam. Ensino, ensino a distância, pós-graduação, pós-graduação a distância, patentes, direitos autorais tão valiosos quanto as patentes e, sobretudo, pesquisas de ponta. A origem da Universidade de Classe Mundial é parte da mundialização do capital sob a predominância financeira. Ela presta serviços da natureza anteriormente referida, orientada pelo seu financiamento, lucros, o que leva à mercantilização das universidades públicas. Isso implica dizer que o trabalho de que presta serviços torna-se predominantemente produtivo na acepção que concebe Marx. A pesquisa é pautada pelas vicissitudes da economia mundial financeirizada. Ela é parte da cadeia produtiva de valor mundializada. Não penso que exista a possibilidade de uma volta, posto que os intelectuais defendem maioritariamente este modelo. (PESQUISADOR 9).

Uma universidade baseada especialmente no desenvolvimento de pesquisa, na fronteira do conhecimento ou aplicada com professores e estudantes de diversos países, meritocrática, produtivista, que concorre com outras em escala global e não nacional. (PESQUISADOR 4).

Las universidades de clase mundial implican la concentración de talentos, gobernabilidad favorable y recursos abundantes para que puedan prestar un servicio no solo al país sino a la región y el mundo. Creo que son criterios muy altos para muchas de las IESs en América Latina, es un deber ser, una meta, pero de NO fácil cumplimiento. (PESQUISADOR 10). 
Apesar das críticas ao modelo de UCM observadas na maioria das respostas, quando o assunto é especificamente internacionalização - a importância da internacionalização da Educação Superior como um objetivo central das universidades latino-americanas -, 73\% responderam que sim, este deveria ser um objetivo central, o que vai ao encontro dos planejamentos institucionais analisados. Ainda que não seja especificado o que o autor compreende como internacionalização, verifica-se que esta dimensão também é essencial para os pesquisadores do tema.

Gráfico 1 - Importância da internacionalização da Educação Superior como um objetivo central das universidades latino-americanas

\section{Entende que a internacionalização deve ser um objetivo central das universidades latino-americanas?}

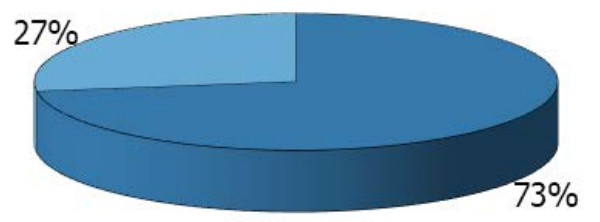

Fonte: Elaborado pelos autores, com base no questionário.

Nas respostas à pergunta "Em sua opinião, existe possibilidade de no concreto-pensado do chão da Universidade se internacionalizar regionalizando e regionalizar internacionalizando? Como e de que forma tendo como base o contexto contemporâneo de América Latina?", podemos perceber algumas pistas sobre esta concepção de internacionalização que os pesquisadores indicam para ALeC.

Nos trechos que seguem, percebemos que há o entendimento de internacionalização em relação com a regionalização, indicando uma perspectiva baseada na solidariedade e no fortalecimento da região.

Considero que sí es posible impulsar la internacionalización a través de la regionalización y en tal sentido el regionalismo juega hoy en día un papel fundamental en la profundización de las relaciones internacionales. Lo importante es el paradigma desde el cual se impulsen estos procesos, 
pues la agenda estatal en la mayoría de los países está atravesada por fines pragmáticos, utilitarismos y centrados en dinamizar el mercado de la Educación Superior. En América Latina tenemos una coyuntura muy difícil por el impulso reciente de los gobiernos de derecha en muchos países; sin embargo, simultáneamente se exacerba la defensa de lo público y se promueven movilizaciones masivas de las universidades y en general del sector educativo y de un importante sector de la sociedad que también la respalda. Esto podría generarnos la visión optimista de que a mediano plazo es posible que se revierta la tendencia y que gane legitimidad y posibilidades los proyectos que se orientan a pensar de otro modo nuestro desarrollo. (PESQUISADOR 4)

Hay importantes iniciativas de universidades de la ALeC que estamos proyectando con redes y asociaciones de integración académica muy potentes e importantes, con una visión alternativa de internacionalización solidaria. (PESQUISADOR 5)

Outros pesquisadores são menos otimistas com as possibilidades de pensar a relação regionalização-internacionalização, indicando aspectos relacionados às dificuldades com a língua e a própria condição periférica da América Latina no cenário global, bem como a articulação da internacionalização com a difusão do modelo de UCM.

Es necesario pensar en la internacionalización, pero aspectos como la suficiencia en otra lengua dificulta el desarrollo de los convenios existentes. (PESQUISADOR 9).

Era possivel, até pouco tempo atrás, devido a políticas regionais de integração no marco do Mercosul e outras instituições regionais. Atualmente, é mais difícil. (PESQUISAOR 7).

A realidade posta consiste em que já existe uma divisão internacional do trabalho acadêmico-científico muito próximo da divisão internacional do trabalho. Não há o que discutir sobre internacionalizar regionalizando ou o oposto. A América Latina e outras regiões do mundo são periferia. Embora Teotônio dos Santos e Ruy Mauro Marini muito tenham escrito sobre a "Teoria Marxista da Dependência" com o foco na superexploração do trabalhador do país de capitalismo periférico e dependente, eles não tinham em vista os professores universitários. Hoje, as instituições universitárias podem ser vistas como de centro ou de periferia. É bobagem falar, portanto, em "se internacionalizar regionalizando e regionalizar internacionalizando". (PESQUISADOR 8). 
Quando a pergunta está diretamente relacionada à universidade na qual o pesquisador atua, 60\% consideram-nas internacionalizadas. Todavia também 60\% da amostra afirma que em sua IES não há oferta de disciplinas em Inglês no âmbito da pós-graduação, o que reafirma o problema apresentado nos PDIs e nos indica que a perspectiva de internacionalização dos pesquisadores não está articulada necessariamente à lógica do modelo de UCM - o qual prevê a necessidade do Inglês como língua da pós-graduação.

No mesmo sentido, quando perguntado sobre seus conhecimentos em relação à existência de parceria com outros países, em termos de mobilidade acadêmica, são destacados EUA (40\%), Portugal e Espanha (50\%), Inglaterra (20\%) e países latino-americanos (70\%). Já quando são perguntados sobre o conhecimento de parcerias com IESs latino-americanas, são citadas Argentina, Brasil, Bolívia, Costa Rica, Chile, Cuba, Ecuador, Honduras, México, Peru, República Dominicana, Uruguay, Veneuzuela. Um dos respondentes indicou que o Conselho Latinoamericano de Ciencias Sociais (CLACSO) administra um conjunto de instituições não orientadas pelos valores da UCM na América Latina.

Sobre o trabalho docente e sua relação com a internacionalização nestas instituições, $70 \%$ da amostra afirma sentir-se pressionada ou induzida a aderir/ compor projetos ou ações internacionais e $73 \%$ indicaram que se sentem pressionados a publicar em revistas internacionais, como mostram os gráficos a seguir.

Gráfico 2 - Sente-se pressionado ou induzido a aderir/compor projetos/práticas ou ações internacionalizados?

\section{Sente-se pressionado ou induzido a aderir/compor projetos/práticas ou ações internacionalizados?}

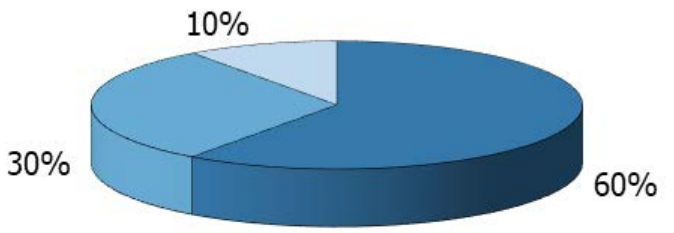

Fonte: Elaborado pelos autores, com base no questionário. 
Gráfico 3 - Sente-se pressionado ou induzido a publicar em revistas internacionais?

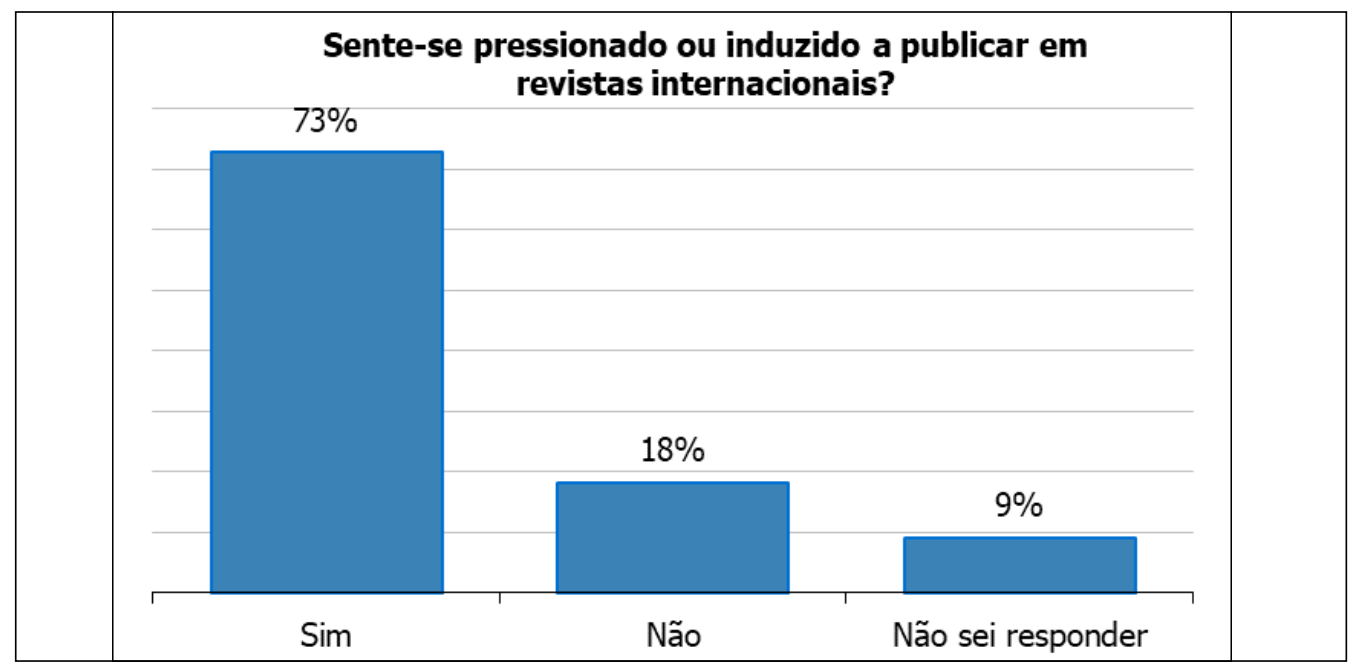

Fonte: Elaborado pelos autores, com base no questionário.

Como tratamos no primeiro item deste artigo, evidencia-se a necessidade de um "novo tipo de docente", que esteja inserido em uma "cultura da investigação", em que a "produtividade científica" deve ser alta (ALTBACH; SALMI, 2011). No entender destes autores:

Este tipo de professor, da mesma forma que as instituições, deve ser, ao mesmo tempo, competitivo e colaborativo, com o duplo objetivo de fazer progressos e forjar uma carreira e uma reputação. Muitas vezes eles trabaIham em equipes, especialmente nas ciências, reconhecendo a importância da colaboração. (ALTBACH; SALMI, 2011, p. 20, tradução nossa).

A disponibilidade para participar de redes, para mobilidade e a procura por melhores condições de trabalho e por carreiras mais promissoras também são colocadas como características deste perfil de profissional, avaliadas de forma positiva. Nas últimas décadas, a lógica da internacionalização tem ganhado relevo na rede de políticas globais como expressão articulada ao movimento de mundialização do capital em sua fase de predominância financeira. A pressão das agências financiadoras, no caso brasileiro - a Coordenação de Aperfeiçoamento de Pessoal de Nível Superior (Capes) -, bem como a criação de programas e projetos de internacionalização vem, por um lado, ampliando as possibilidades de 
inter-relação e formação de redes com outros países, e, por outro lado, induzindo uma lógica acadêmica voltada para a perspectiva quantitativa (em termos de produção), em Inglês a "todo custo" e em atendimento à promoção do mercado da mobilidade internacional.

\section{ALGUMAS CONSIDERAÇÕES NADA FINAIS}

Com este artigo, corroboramos a hipótese que viemos desenvolvendo de que, para o caso específico das universidades latino-americanas e caribenhas, assim como ocorrem em outros países da periferia do capitalismo, um outro perfil de UCM vem sendo gestado/difundido, sendo este essencialmente pautado pela internacionalização.

Podemos constatar que esse outro perfil de UCM é elaborado nos próprios documentos dos Ols, quando trata da especificidade de alguns centros de excelência, destacando potencial em se tornarem UCM, bem como seus problemas, criando uma espécie de núcleo problemático, que acaba servindo de "receita" para adequação aos critérios de uma "UCM de segundo tipo" (THIENGO; ALMEIDA; BIANCHETTI, 2019a). Um exemplo tácito desta lógica é o fato de que algumas IESs declaram como objetivo em seus PDIs a articulação com Universidades de Classe Mundial como estratégia relevante para seu desenvolvimento institucional, reforçando a ideia de formação de redes com os países que compõem o eixo dinâmico do capital.

Neste sentido, a internacionalização sobressai como a principal forma de adequação a este modelo, como pudemos verificar nos PDIs das instituições (THIENGO; ALMEIDA; BIANCHETTI, 2019b), ainda que, nem sempre, contemplem seu objetivo precípuo de "atrair e concentrar talentos", sendo esta a principal função da internacionalização para as UCMs.

Nos dados coletados dos questionários sobre o tema, percebemos que, apesar de a lógica de UCM não estar nomeadamente colocada enquanto projeto na maioria das IESs latino-americanas, os pesquisadores conhecem o tema e, em sua maioria, destacam os problemas do modelo enquanto projeto de universidade mundial. Todavia, outra vez, a internacionalização é compreendida por alguns pesquisadores de forma mais "otimista" em termos de projeto para as universidades latino-americanas, especialmente no que tange a formas de internacionalização 
articuladas à regionalização, ainda que esta lógica não se consubstancie como central nos PDIs analisados.

Os desdobramentos da difusão da perspectiva de Classe Mundial, por sua vez, já podem ser verificados na intensificação ainda maior do trabalho docente, que passa a ter de responder a outras demandas de caráter "internacionalizador", que vão desde o domínio da Língua Inglesa até a criação de redes internacionais, parcerias em artigos e publicações em revistas internacionais. Quem sabe já não estão sendo forjados os novos "docentes excelentes" com "essência internacional", como vem propondo os Ols.

Por fim, reiteramos o caráter em andamento da pesquisa que dá origem a este artigo e a não utilização de todos os dados do questionário mencionado, considerando os limites de espaço do texto e o recorte proposto a este artigo. Também frisamos o limite da nossa amostra de respondentes dos questionários, o que inviabiliza generalizações ou afirmações mais categóricas em relação ao tema. Sendo assim, ainda que com mais indicativos e perguntas do que, essencialmente, respostas, finalizamos este texto no intuito de lançar luz a algumas questões pouco problematizadas e instigar novas pesquisas.

\section{REFERÊNCIAS}

ALTBACH, P. et al. Paying the professoriate: a global comparison of compensation and contracts. London: Routledge, 2012.

ALTBACH, P.; SALMI, J. The road to academic excellence: the making of world-class research universities. Washington, USA: The World Bank, 2011.

ARAÚJO, E; FERREIRA, F. A fuga de cérebros: um discurso multidimensional. In: ARAÚJO, E.; FONTES, M.; BENTO, S. (Ed.). Para um debate sobre mobilidade e fuga de cérebros. Braga: Centro de Estudos de Comunicação e Sociedade, 2013. p. 58-82.

INSTITUTO TECNOLÓGICO Y DE ESTUDIOS SUPERIORES DE MONTERREY. Plan Estratégico 2020 del Tecnológico de Monterrey. Monterrey: ITMS, 2016.

MAUÉS, O. A expansão e a internacionalização da educação superior. In: REUNIÃO NACIONAL DA ANPED, 37., Florianópolis, 2015. Anais [...]. Rio de Janeiro: Anped, 2015. p. 1-17. Disponível em: http://www.anped.org.br/sites/default/files/trabalho-gt11-3897. pdf. Acesso em: 10 ago. 2017. 
MOROSINI, M. Internacionalização na produção de conhecimento em IES brasileiras: cooperação internacional tradicional e cooperação internacional horizontal. Educação em Revista, Belo Horizonte, v. 27, n. 1, p. 99-112, abr. 2011.

PONTIFICIA UNIVERSIDAD CATÓLICA DE CHILE. Plan De Desarrollo 2015 - 2020. Santiago, out. 2015. Disponível em: https://www.uc.cl/site/assets/files/5000/plan_ desarrollo2015-20.pdf. Acesso em: 11 mar. 2020.

ROBERTSON, S. L. Challenges facing universities in a globalising world. Bristol: Centre for Globalisation, Education and Societies, 2010.

SADLAK, J.; CAI, L. N. (Ed.). The world-class university as part of a new higher education paradigm: from institutional qualities to systemic excellence. Bucharest: Unesco-Cepes, 2009

SALMI, J. El desafío de crear universidades de rango mundial. Bogotá: Mayol Ediciones, 2009.

SGUISSARDI, V. Estudo diagnóstico da política de expansão da (e acesso à) Educação Superior no Brasil - 2002-2012. Brasília: Sesu: OEl, 2014. [mimeo].

SILVA JÚNIOR, J. R. The new brazilian university - a busca de resultados comercializáveis: para quem? Relatório de Pesquisa Fapesp/CNPq. São Carlos, SP: Ufscar; Tempe, Phoenix: ASU, 2015.

THIENGO, L. C.; ALMEIDA, M. L. P.; BIANCHETTI, L. Universidade de Classe Mundial no contexto Latino-Americano e Caribenho: o que dizem os Organismos Internacionais. Educar em revista, Curitiba, v. 35, p. 259-78, 2019a.

THIENGO, L. C.; ALMEIDA, M. L. P.; BIANCHETTI, L. O modelo de classe mundial e as universidades latino-americanas e caribenhas: tendências que se anunciam? Revista Ibero-Americana de Estudos em Educação, Araraquara, SP, v. 14, n. esp. 3, p. 1621-37, out. 2019b.

UNIVERSIDAD DE LOS ANDES. Programa de Desarrollo Integral. Colômbia, 2016.

UNIVERSIDADE DE SÃO PAULO (USP). Plano de Desenvolvimento Institucional 2012-2017. São Paulo: USP, 2011.

UNIVERSIDADE FEDERAL DO RIO GRANDE DO SUL. Plano de Desenvolvimento Institucional 2016-2026. Porto Alegre: UFRGS, 2016. 
UNIVERSIDADE NACIONAL DO MÉXICO. Plan de Desarrollo Institucional 2015-2019. México: UNAM, 2015.

\section{Sobre os autores:}

Lara Carlette Thiengo: Doutora em Educação pela Universidade Federal de Santa Catarina (UFSC). Professora adjunta da Universidade Federal dos Vales do Jequitinhonha e Mucuri (UFVJM), Campus Diamantina. E-mail: laracarlette@gmail.com, Orcid: http://orcid.org/0000-0003-3593-4746

Lucídio Bianchetti: Doutor em Educação: História, Política, Sociedade pela Pontifícia Universidade Católica de São Paulo (PUC-SP). Professor do Programa de PósGraduação em Educação na Universidade Federal de Santa Catarina (UFSC). E-mail: lucidio.bianchetti@pq.cnpq.br, Orcid: http://orcid.org/0000-0003-2850-4692

Recebido em 2 de novembro de 2019 Aprovado em 14 de fevereiro de 2020 